\title{
Miliary pulmonary nodules due to Mycobacterium xenopi in a steroid-induced immunocompromised patient successfully treated with chemotherapy: a case report
}

Yoshio Okano ${ }^{1}$, Tsutomu Shinohara ${ }^{2 *}$, Shino Imanishi ${ }^{1}$, Naoki Takahashi ${ }^{1}$, Nobuhito Naito ${ }^{1}$, Takanari Taoka', Naoki Kadota ${ }^{1}$ and Fumitaka Ogushi ${ }^{1}$

\begin{abstract}
Background: Mycobacterium xenopi-infected patients have a high prevalence of pulmonary cavities and nodules. However, the clinical course for patients with miliary nodules due to M. xenopi has not yet been reported.

Case presentation: We encountered a case of miliary nodules with gradually worsening coughing and sputum production in a 44-year-old male who had renal dysfunction due to glomerulosclerosis with a decade-long history of steroid therapy. Although we started anti-tuberculosis treatment on clinical suspicion of miliary tuberculosis, cultures of sputum and bronchial lavage were both positive for M. xenopi. The patient was successfully treated with rifampin, ethambutol and clarithromycin, without fibrosis. It was unclear whether the miliary pattern was induced by hematogenous or endobronchial spread of the M. xenopi infection.

Conclusion: Even when clinical and radiological disease manifestations are similar to those of miliary tuberculosis, M. xenopi infection should be considered in the differential diagnosis of miliary nodules.
\end{abstract}

Keywords: Mycobacterium xenopi, Miliary nodules, Immunocompromised patient

\section{Background}

Mycobacterium xenopi is one of the common causes of nontuberculous mycobacteria (NTM) pulmonary disease, especially in Canada, France and the United Kingdom [1-3]. In comparison with M. avium complex (MAC), M. xenopi-infected patients were found to have a high prevalence of pulmonary cavities and nodules, and rarely present a nodular bronchiectatic form [4]. A large number of patients with pulmonary cavities due to M. xenopi simultaneously had computed tomography (CT) findings of random nodules or consolidation rather than the fibrocavitary form [4]. The management of individual patients with $M$. xenopi is difficult, since a standard treatment has not been established.

\footnotetext{
* Correspondence: shinoharat@kochi2.hosp.go.jp

${ }^{2}$ Department of Clinical Investigation, National Hospital Organization Kochi

Hospital, 1-2-25 Asakuranishimachi, Kochi 780-8077, Japan

Full list of author information is available at the end of the article
}

Regarding the random nodules, 4 cases of miliary nodules due to $M$. xenopi with acquired immunodeficiency syndrome were reported by Bankier et al. However, the radiological evaluation of these cases was made by chest X-ray, not by CT. In addition, the clinical course for the patients was not described [5]. In this report, we present a case of chest CT-proven miliary nodules due to $M$. xenopi without cavities and consolidations in a steroid-induced immunocompromised patient successfully treated with chemotherapy.

\section{Case presentation}

A 44-year-old male, who had renal dysfunction due to glomerulosclerosis with a decade-long history of steroid therapy (10-20 mg of prednisone per day), visited our department because of gradually worsening coughing and sputum production. He had no past history of any pulmonary disease, such as chronic obstructive pulmonary disease (COPD), tuberculosis or bronchial asthma. 
The results of a physical examination were normal. Laboratory data were as follows: white blood cell count, 10630/ $\mu$ l (neutrophils, $91.6 \%$ ); hemoglobin, $12.5 \mathrm{~g} / \mathrm{dl}$; platelet count, $61.2 \times 10^{4} / \mu \mathrm{l} ; \quad$ C-reactive protein, $6.27 \mathrm{mg} / \mathrm{dl}$; creatinine, $1.64 \mathrm{mg} / \mathrm{dl}$. Chest X-ray and CT showed a high number of miliary nodules in both lungs without consolidations or cavities (Fig. 1a and b). Underlying pulmonary diseases, such as emphysema and bronchiectasis, were not observed. Abdominal CT and magnetic resonance imaging of the spine detected no extrapulmonary lesions. Although a sputum acid-fast bacillus smear was positive, polymerase chain reaction (PCR) tests for M. tuberculosis, M. avium and M. intracellurare of the sputum were all negative. On clinical suspicion of miliary tuberculosis, we started quadruple therapy (isoniazid, rifampin (RFP), ethambutol (EB) and pyrazinamide) without dose reduction of prednisone $(10 \mathrm{mg} /$ day $)$. Then, we carried out a bronchoscopic examination, and transbronchial lung biopsy detected small granuloma (Fig. 1c and d) and Ziehl-Neelsen staining-positive bacillus bodies (Fig. 1e). Acid-fast bacillus smear and PCR tests of bronchial lavage showed the same results as sputum. Later, the culture of sputum and bronchial lavage obtained mycobacterium colonies, and the isolates from both samples were identified as $M$. xenopi by DNA-DNA hybridization (DDH). Since patients infected with $M$. heckeshornense may have been included in the cases that were diagnosed as $M$. xenopi disease by $\mathrm{DDH}$, we reconfirmed that the isolate from bronchial lavage was $M$. xenopi by sequence analyses of the $16 \mathrm{~S}$ rRNA gene, rpoB and hsp65 [6]. After the final diagnosis of M. xenopi pulmonary infection was established, we changed the quadruple therapy to treatment with RFP (450 mg/day), EB (750 mg/day) and clarithromycin (CAM) $(800 \mathrm{mg} /$ day). Chemotherapy was continued for a total period of 15 months without side effects, and steroid therapy for glomerulosclerosis was also continued without dose modification. Sputum cultures yielded no mycobacteria in the last 12 months. After the chemotherapy, chest CT showed a prominent reduction in the size and number of miliary nodules without fibrosis (Fig. 1f).

\section{Discussion}

Clinical and radiological disease manifestations of $M$. xenopi infection vary according to each person's immunological status, and can be classified into three groups: (1) a cavitary form in patients with pre-existing pulmonary disease; (2) a solitary nodular form in immunocompetent patients and (3) an acute infiltrate form in immunosuppressed patients [2]. Although multiple small nodules $(<5 \mathrm{~mm})$ coexisting with a predominant form were a common finding in patients with $M$. xenopi pulmonary infection, the mean number is about $10-16$ per patient $[4,7]$. Therefore, the CT-proven miliary pattern without cavities and consolidations observed in our immunocompromised patient could be a distinct entity.

Previously, O'Connell et al. reported an autopsy-based series of pulmonary or disseminated nontuberculous mycobacterial disease. In that report, a miliary pattern was noted in 2 of the 5 disseminated patients with mycobacterial lung involvement, but not in the 11 primary pulmonary mycobacterial diseases without extrapulmonary

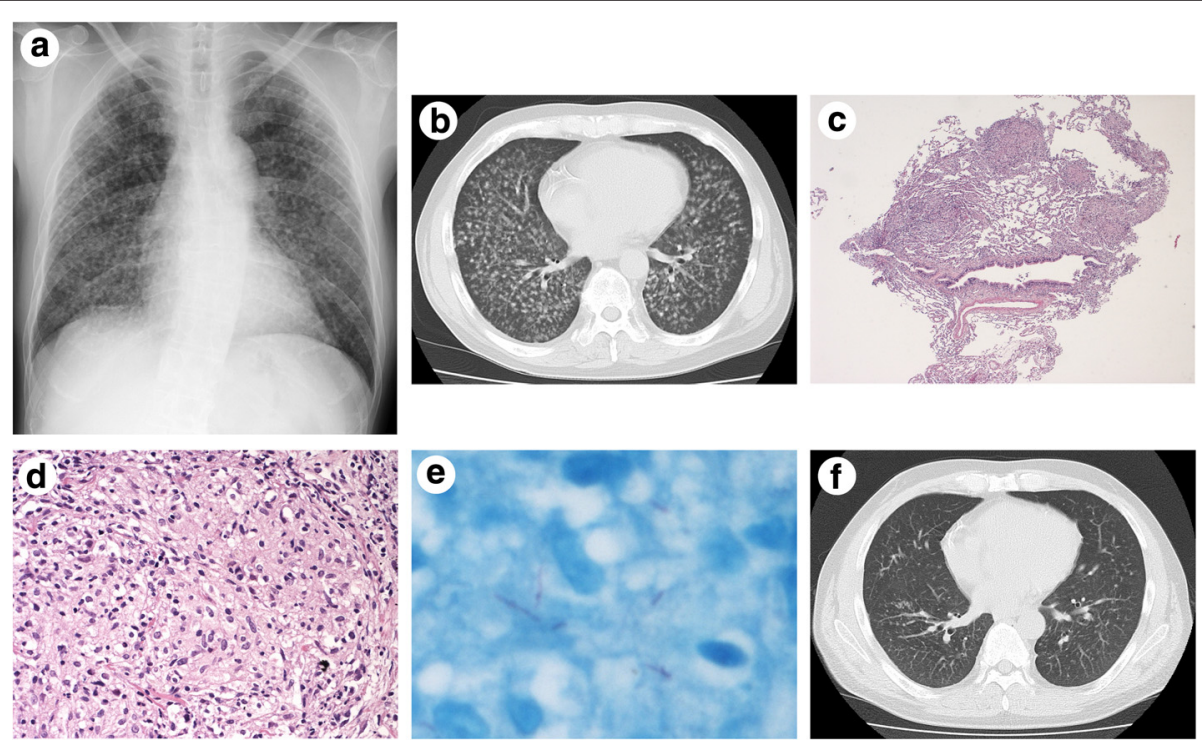

Fig. 1 Chest X-ray (a), CT (b and $\mathbf{f}$ ) and pathological findings of transbronchial lung biopsy (c and $\mathbf{d}$, hematoxylin and eosin staining; $\mathbf{e}$, Ziehl-Neelsen staining). $\mathbf{a}$ and $\mathbf{b}$ : A high number of miliary nodules in both lungs without consolidations and cavities at presentation. c and $\mathbf{d}$ : Granulomatous inflammation (c, low-power field; $\mathbf{d}$, high-power field). e: Bacillus bodies seen as a bright red rod. f: Marked improvement in miliary nodules after 15 months of chemotherapy 
infection [8]. In addition, miliary pulmonary infection with a macropapular rash on extremities caused by $M$. terrae in an immunocompromised patient was reported [9]. Miliary pulmonary infection due to nontuberculous mycobacteria in a patient without extrapulmonary infections may be extremely rare.

Although a miliary pattern is usually induced by the hematogenous spread of infection or tumor cells, this pattern with or without ground-glass opacities sometimes can be seen in so-called hot tub lung (HTL) caused by inhalation of water aerosol containing NTM, especially the MAC [10-12]. There seems to be quite a controversy over whether HTL is a direct appearance of mycobacterial infection or is a hypersensitivity pneumonitis (HP). Because the sputum cultures continued to be positive for 6 weeks after initiation of chemotherapy, an infectious process was probably involved in the pathogenesis in our case. While acid-fast bacillus cultures of sputum, tissue and bronchial lavage from patients with HTL are positive at high rates, HTL usually manifests spontaneous or steroid-induced improvement after cessation of hot tub exposure without antimycobacterial treatment [12]. It was also reported in a mouse model that HTL develops through mycobacterial engagement with Toll-like receptor 9/Myeloid differentiation factor 88 signaling in pulmonary CD11b-positive dendritic cells, regardless of the mycobacterial infectious capacity [13]. In addition, intravesical administration of bacillus Calmette-Guerin (BCG) against urothelial cancer occasionally induces systemic hypersensitivity reactions, including pneumonitis, without detection of BCG in corresponding organs [14]. These data indicate that NTMs have pathogenic potential not only as infectious microorganisms, but also as highly immunogenic substances for HP. Although HTL generally appears in immunocompetent patients with no preexisting lung disease [12], the hypersensitivity phenomenon may have overlapped, to a greater or lesser degree, with an infectious process in the pathogenesis in our case. From the above-mentioned points, the possibility remains that the miliary pattern of our patient resulted from endobronchial spread of the M. xenopi infection with hypersensitivity to M. xenopi antigens.

Although a standard treatment for $M$. xenopi has not been established, ATS/IDSA recommends an RFP, EB and CAM-containing regimen [15]. In general, the prognosis for the hematogenous spread of infection in immunocompromised patients is poor, but a prognosis for NTM miliary infection has not been well documented. In this case, treatment with RFP, EB and CAM was effective for miliary pulmonary infection caused by $M$. xenopi even in an immunocompromised patient. Further clinical studies on the pathophysiology related to $M$. xenopi miliary infection are needed in order to improve the management of this rare condition.

\section{Conclusion}

M. xenopi infection should be considered in the differential diagnosis of miliary pulmonary nodules, even when the clinical and radiological disease manifestations are similar to those of miliary tuberculosis.

\section{Abbreviations \\ NTM, nontuberculous mycobacteria; M. xenopi, Mycobacterium xenopi: MAC, M. avium complex; CT, computed tomography; COPD, chronic obstructive pulmonary disease; PCR, polymerase chain reaction; RFP, rifampin; EB, ethambutol; DDH, DNA-DNA hybridization; CAM, clarithromycin; HTL, hot tub lung; HP, hypersensitivity pneumonitis; BCG, bacillus Calmette-Guerin}

\section{Acknowledgements}

We thank Keishi Naruse (Division of Pathology, National Hospital Organization National Kochi Hospital), Yukihisa Komatsu (Division of Radiology, National Hospital Organization National Kochi Hospital) for their contributions, and Yuko Kazumi (Department of Mycobacterium Reference and Research, Research Institute of Tuberculosis, Japan Anti-Tuberculosis Association) for molecular genetic studies.

\section{Funding}

No funding has been received for this project.

Availability of data and materials

All the data supporting our findings is contained within the manuscript.

\section{Authors' contributions}

YO drafted the initial manuscript. TS edited and submitted the manuscript. $\mathrm{SI}, \mathrm{NT}, \mathrm{NN}, \mathrm{T}$, and NK were involved in diagnosing and treating the patient. FO was the attending physician throughout the disease course. All authors read and approved the final manuscript.

\section{Competing interests}

The authors declare that they have no competing interests.

\section{Consent for publication}

Written informed consent was obtained from the patient for publication of this case report and any accompanying images. A copy of the written consent is available for review by the Editor-in-Chief of this journal.

Ethics approval and consent to participate

Ethical approval to report this case was not required.

Framework

We followed the CARE guidelines.

\section{Author details}

'Division of Pulmonary Medicine, National Hospital Organization Kochi Hospital, 1-2-25 Asakuranishimachi, Kochi 780-8077, Japan. ${ }^{2}$ Department of Clinical Investigation, National Hospital Organization Kochi Hospital, 1-2-25 Asakuranishimachi, Kochi 780-8077, Japan.

Received: 27 January 2016 Accepted: 1 June 2016

Published online: 10 June 2016

\section{References}

1. Marras TK, Chedore P, Ying AM, Jamieson F. Isolation prevalence of pulmonary non-tuberculous mycobacteria in Ontario, 1997-2003. Thorax. 2007:62:661-6.

2. Andréjak C, Lescure FX, Pukenyte E, Douadi Y, Yazdanpanah Y, Laurans G, et al. Mycobacterium xenopi pulmonary infections: a multicentric retrospective study of 136 cases in North-east France. Thorax. 2009;64:291-6.

3. Management of opportunist mycobacterial infections: Joint Tuberculosis Committee Guidelines. Subcommittee of the Joint Tuberculosis Committee of the British Thoracic Society. Thorax. 2000;55:210-8.

4. Carrillo MC, Patsios D, Wagnetz U, Jamieson F, Marras TK. Comparison of the spectrum of radiologic and clinical manifestations of pulmonary disease 
caused by Mycobacterium avium complex and Mycobacterium xenopi. Can Assoc Radiol J. 2014;65:207-13.

5. Bankier AA, Stauffer F, Fleischmann D, Kreuzer S, Strasser G, Mossbacher U, et al. Radiographic findings in patients with acquired immunodeficiency syndrome, pulmonary infection, and microbiologic evidence of Mycobacterium xenopi. J Thorac Imaging. 1998;13:282-8.

6. Morimoto K, Kazumi Y, Maeda S, Yoshimori K, Yoshiyama T, Ogata H et al. Mycobacterium heckeshornense lung infection that was diagnosed as Mycobacterium xenopi disease by DNA-DNA hybridization (DDH). Intern Med. 2011;50:1251-3.

7. Marras TK, Wagnetz U, Jamieson FB, Patsios DA. Chest computed tomography predicts microbiological burden and symptoms in pulmonary Mycobacterium xenopi. Respirology. 2013;18:92-101.

8. O'Connell ML, Birkenkamp KE, Kleiner DE, Folio LR, Holland SM, Olivier KN. Lung manifestations in an autopsy-based series of pulmonary or disseminated nontuberculous mycobacterial disease. Chest. 2012;141:1203-9.

9. Peters EJ, Morice R. Miliary pulmonary infection caused by Mycobacterium terrae in an autologous bone marrow transplant patient. Chest. 1991;100:1449-50.

10. Fahim A, Khan MN. An unusual cause of miliary radiographic pattern. BMJ Case Rep. 2011. doi:10.1136/bcr.10.2011.5060.

11. Zota V, Angelis SM, Fraire AE, McNamee C, Kielbasa S, Libraty DH. Lessons from Mycobacterium avium complex-associated pneumonitis: a case report. J Med Case Rep. 2008;2:152.

12. Hanak V, Kalra S, Aksamit TR, Hartman TE, Tazelaar HD, Ryu JH. Hot tub lung: presenting features and clinical course of 21 patients. Respir Med. 2006;100:610-5.

13. Daito H, Kikuchi T, Sakakibara T, Gomi K, Damayanti T, Zaini J, et al. Mycobacterial hypersensitivity pneumonitis requires TLR9-MyD88 in lung CD11b + CD11c + cells. Eur Respir J. 2011;38:688-701.

14. Israel-Biet D, Venet A, Sandron D, Ziza JM, Chretien J. Pulmonary complications of intravesical Bacille Calmette-Guérin immunotherapy. Am Rev Respir Dis. 1987;135:763-5.

15. Griffith DE, Aksamit T, Brown-Elliott BA, Catanzaro A, Daley C, Gordin F, et al. An official ATS/IDSA statement: diagnosis, treatment, and prevention of nontuberculous mycobacterial diseases. Am J Respir Crit Care Med. 2007;175:367-416.

\section{Submit your next manuscript to BioMed Central and we will help you at every step:}

- We accept pre-submission inquiries

- Our selector tool helps you to find the most relevant journal

- We provide round the clock customer support

- Convenient online submission

- Thorough peer review

- Inclusion in PubMed and all major indexing services

- Maximum visibility for your research

Submit your manuscript at wuw biomedcentral.com/submit

C Biomed Central 